\title{
On contour representation of two dimensional patterns
}

\section{T. BANU-DEMERGIAN and G. STEFANESCU}

\section{ABSTRACT.}

Two-dimensional patterns are used in many research areas in computer science, ranging from image processing to specification and verification of complex software systems (via scenarios). The contribution of this paper is twofold. First, we present the basis of a new formal representation of two-dimensional patterns based on contours and their compositions. Then, we present efficient algorithms to verify correctness of the contourrepresentation. Finally, we briefly discuss possible applications, in particular using them as a basic instrument in developing software tools for handling two dimensional words.

\section{REFERENCES}

[1] Asarin, E., Caspi, P., and Maler, O., Timed regular expressions, Journal of the ACM, 49 (2002), 172-206

[2] Banu-Demergian, I. T., Paduraru, C. I., and Stefanescu, G., A new representation of two-dimensional patterns and applications to interactive programming, in Proceedings FSEN 2013, LNCS 8161, Springer, 2013, 183-198

[3] Bentley, J. and Ottmann, T. A., Algorithms for reporting and counting geometric intersections, IEEE Transactions on Computers, 100 (1979), 643-647

[4] Bribiesca, E. and Verlade, C., A formal language approach for a 3D curve representation, Computers \& Mathematics with Applications, 42 (2001), 1571-1584

[5] Conway, J. H., Regular Algebra and Finite Machines, Chapman and Hall, 1971

[6] Dragoi, C. and Stefanescu, G., AGAPIA v0.1: A programming language for interactive systems and its typing systems, ENTCS, 203 (2008), 69-94

[7] Freeman, H., On the encoding of arbitrary geometric configurations, IRE Transactions on Electronic Computers, 2 (1961), 260-268

[8] Garg, V. and Ragunath, M. T., Concurrent regular expressions and their relationship to Petri nets, Theoretical Computer Science, 96(1992), 285-304

[9] Giammarresi, D. and Restivo, A., Two-dimensional languages, in Handbook of Formal Languages. Vol. 3: Beyond Words, Springer-Verlag, 1997, 215-265

[10] Goldin, D., Smolka, S., and Wegner, P., Eds., Interactive Computation: The New Paradigm, Springer, 2006

[11] Kleene, S. C., Representation of events in nerve nets and finite automata, in Automata Studies, Princeton University Press, 1956, 3-41

[12] Kozen, D., A completeness theorem for Kleene algebras and the algebra of regular events, in Proceedings LICS 1991, 214-225

[13] Kaneko, T. and Okudaira M., Encoding of arbitrary curves based on the chain code representation, IEEE Transactions on Communications, 33 (1985), 697-707

[14] Liu, Y. K. and Zalik, B., An efficient chain code with Huffman coding, Pattern Recognition, 38 (2005), 553-557

[15] Stefanescu, G., Algebra of networks: Modeling simple networks as well as complex interactive systems, in Proof and System Reliability, Kluwer, 2002, 49-78

[16] Stefanescu, G., Interactive systems with registers and voices, Fundamenta Informaticae, 73 (2006), 285-306

Received: 18.12.2013; In revised form: 10.12.2014; Accepted: 17.12.2014

2010 Mathematics Subject Classification. 68Q10, 68Q45, 68R01.

Key words and phrases. Regular expressions, two-dimensional patterns, contours, structured interactive programming, formal methods.

Corresponding author: I. T. Banu-Demergian; th_iulia84@yahoo.com 
DEPARTMENT OF COMPUTER SCIENCE

UNIVERSITY OF BUCHAREST, ROMANIA

E-mail address: iulia.banu@ fmi . unibuc.ro

E-mail address: gheorghe. stefanesculfmi .unibuc.ro 